\title{
बएस
}

Open Library of Humanities

\section{On covariation between nasal consonant weakening and anticipatory vowel nasalization: Evidence from a Caribbean and a non-Caribbean dialect of Spanish}

Silvina Bongiovanni, Department of Romance and Classical Studies, Michigan State University, East Lansing, MI, USA, bongiov8@msu.edu

Dialects of Spanish can be (broadly) categorized as 'preferring' a coronal or a velar realization for the word-final nasal consonant ([n]- and [n] -dialects, respectively). Scholars have observed that the phonetic and phonological details of the pre-nasal vowel among [ $\eta]$-dialects differ from those of [n]-dialects. The prevailing view in Spanish phonology is that backing and nasalization are part of a more general process of weakening: / $\mathrm{n} /$ goes [ $\mathrm{\eta}$ ] before going to zero, leaving nasalization 'residue' in the pre-nasal vowel. Despite the well-documented dialectal differences and covariation pressures in anticipatory vowel nasalization, instrumental studies examining Spanish weakening of the nasal consonant together with anticipatory vowel nasalization are scarce. To this end, I compare co-variation between the word-final nasal consonant and anticipatory vowel nasalization in an [ $\mathrm{\eta}]$-dialect and an [n]- one. Twenty-eight speakers from Santo Domingo (Dominican Republic) and twenty-six from Buenos Aires (Argentina) were recorded with a nasometer. Findings revealed that both dialects are susceptible to covariation pressures. At the same time, despite exhibiting similar degrees of nasal consonant weakening, Santo Domingo Spanish exhibits earlier onset of nasalization nonetheless, suggesting that dialectal differences in the temporal extent of anticipatory vowel nasalization cannot be exclusively ascribed to nasal consonant weakening.

Laboratory Phonology: Journal of the Association for Laboratory Phonology is a peer-reviewed open access journal published by the Open Library of Humanities. (c) 2021 The Author(s). This is an open-access article distributed under the terms of the Creative Commons Attribution 4.0 International License (CC-BY 4.0), which permits unrestricted use, distribution, and reproduction in any medium, provided the original author and source are credited. See http://creativecommons.org/licenses/by/4.0/. ๖ OPEN ACCESS 


\section{Introduction}

Dialects of Spanish can be (broadly) categorized as 'preferring' a coronal or a velar realization for the word-final nasal consonant ([n]- and [n]-dialects, respectively). Time and again, scholars have observed that the phonetic and phonological details of the pre-nasal vowel among velar dialects differ from those of [n]-dialects (Campos-Astorkiza, 2012; Colantoni, 2011; Hualde, 2014; Lederer, 2003; Lipski, 2011; Vaquero, 1996). The prevailing view in Spanish phonology is that backing of $/ \mathrm{n} /$ and nasalization of the pre-nasal vowel are part of a more general process of weakening: /n/ goes to [ $\mathrm{n}$ ] before going to zero, leaving nasalization 'residue' in the pre-nasal vowel. Covariation between nasal consonant weakening and anticipatory vowel nasalization, thus, has been at the heart of dialectal differences in Spanish phonology.

In this article, I present a nasometric study of word-final /n/ weakening and anticipatory vowel nasalization in two dialects of Spanish, Buenos Aires (Argentina) and Santo Domingo (Dominican Republic). Two sets of findings motivate the present research. First, /n/ weakening among [y]-dialects is well-documented, impressionistically, as well as instrumentally (Cedergren \& Sankoff, 1975; Colantoni \& Kochetov, 2012; D’Introno \& Sosa, 1988; Haché de Yunén, 1981; Kochetov \& Colantoni, 2011; López Morales, 1980; Ramsammy, 2011, 2013; Terrell, 1975; Trigo, 1988). Second, when compared to [n]-dialects, [n]-dialects also show earlier onset of nasalization (Bongiovanni, 2021, Lederer, 2000, cited in Lederer, 2003). Despite the well-documented dialectal differences and covariation pressures in anticipatory vowel nasalization, instrumental studies examining Spanish weakening of the nasal consonant together with anticipatory vowel nasalization are scarce, if not lacking. The present study fills this gap. Findings show the same trading relationship across dialect groups. One crucial difference between dialects is the finding that despite exhibiting similar degrees of nasal consonant weakening (or lack thereof), Santo Domingo Spanish presents earlier onset of nasalization nonetheless. These results, thus, suggest that differences in the temporal extent of anticipatory vowel nasalization cannot be exclusively ascribed to nasal consonant weakening, and offer additional evidence regarding phonetic, and putatively phonological, differences across [n]- and [n]-dialects.

In the background section, I review the relevant phonological and phonetic facts that motivate the present study, as well as research on the nasal consonant-vowel nasalization trading relationship. The research methods are presented in Section 3 and findings are unpacked in Section 4. The article ends with Section 5 where I discuss the results and offer concluding remarks.

\section{Background}

\subsection{Variation in the Spanish nasal system}

Spanish nasal consonants are traditionally described as exhibiting a three-way place-of-articulation contrast. As shown in 1, bilabial, alveolar, and palatal nasal consonants freely occur in the syllable onset. 
(1)
i. cama /ká.ma/ 'bed'
mata /má.ta/ 's/he kills'
ii. cana /ká.na/ 'grey hair'
nata /ná.ta/ 'cream'
iii. caña /ká.na/ 'fishing rod, reed'
ñata /ná.ta/ 'nose' (colloquial)1

In the coda, the most common nasal is alveolar, which exhibits considerable contextual and regional variation. Pre-consonantal $/ \mathrm{n} /$ is homorganic with the consonant that follows, as shown in the data in 2 . Crucial to this article is the wide regional variation that $/ \mathrm{n} /$ exhibits in the word final domain (see examples in 3). As mentioned previously, dialects of Spanish can be categorized as retaining or exhibiting velarization and deletion of final /n/ (i.e., [n]- and [y]-dialects), both in assimilating contexts (i.e., preceding a consonant, whether word-internally or across word-boundary, 3iii and 3iv) and in non-assimilating contexts (e.g., pre-vocalically and pre-pausally, 3i and 3ii; Baković, 2001; Cedergren \& Sankoff, 1975; D’Introno \& Sosa, 1988; Haché de Yunén, 1981; Hyman, 1956; López Morales, 1980; Muñiz-Cachón, 2002; Salvador, 1987; Terrell, 1975; Trigo, 1988). Far from being relegated to an enclosed area, velarizing dialects cover vast areas of the Hispanophone world. In Spain, all corners of the peninsula report pockets of [y]-dialects, from Galicia and Asturias in the Northwest, to Andalucía and Murcia in the South, and León and Extremadura in the West, including the Canary Islands well in the East (Muñiz-Cachón, 2002; Salvador, 1987). In the Americas, in addition to the Hispanic Caribbean, [y]-dialects have also been reported in Central America, Colombia, Ecuador, Venezuela, and Cuba (Hyman, 1956).
i. un beso [um.bé.so] 'a kiss'
ii. informe [im.fór.me] 'report'
iii. canto [kán.ța] 'I sing'
iv. ansia [án.sja] 'anxiety'
v. ancho [ánj.tfo] 'wide'
vi. ángel [áp.xel] 'angel'

(3)
i. pan 'bread'
a. [pán]
ii. pan agrio 'bitter bread'
b. [pán] [páp] [pã]
iii. pan casero 'homemade bread'
a. [pá.ná.yrjo]
b. [pá.ná.yrjo] [pá.yá.yrjo] [pã.yrjo]
a. [pán.ká.sé.ro]
iv. pan turco 'turkish bread'
b. [pán.ká.sé.ro] [pã.ka.sé.ro]
a. [pan.tur.ko]
b. [pan.țur.ko] [pay.tur.ko] [pã.tur.ko]

\footnotetext{
${ }^{1}$ In word-initial position, the palatal nasal $[n]$ is found in a limited set of words due to its historical evolution.
} 
There is some disagreement among scholars regarding the phonological derivation that accounts for velarization, that is, (b) examples in 3. Harris (1984) posits that the choice of $[\mathrm{n}]$ or $[\mathrm{n}]$ is the result of dialect-specific default-place of articulation. For others, velar is an unmarked place of articulation that surfaces to interpret the [+ consonantal] feature of a place-less nasal (Baković, 2001; Trigo, 1988). Piñeros (2006), on the other hand, argues for [ $\mathrm{y}]$ as the result of assimilation to the pre-nasal vowel. Regardless of the differences in the derivation, the traditional view is that velarization of $/ \mathrm{n} /$ is part of a process of nasal consonant attenuation, ${ }^{2}$ that by way of consonant deletion, leads to nasalization of the pre-nasal vowel. Since [n]-dialects do not exhibit velarized variants, they are assumed to be exempt from the weakening trends. Uber (1984) constitutes an exception. For the author, velarization and vowel nasalization do not represent successive stages in the weakening process: Both [Vn] and [Vy] can lead to nasalized vowels. Thus, unlike previous proposals, Uber's (1984) analysis does not preclude [n]-dialects of undergoing the same weakening-nasalization pressures as [n]-dialects.

Even though the data in 3 presents the variation in a cut-and-dried fashion, among [n]-dialects, /n/ weakening is quite variable. Sociolinguistic (variationist) research has shown that some [n]-dialects velarize more than others (e.g., Venezuela/Puerto Rico versus Dominican Republic; D’Introno \& Sosa, 1988; Haché de Yunén, 1981; López Morales, 1980), and/or that may show more instances of $/ \mathrm{n} /$ deletion compared to any other variants, including velarization (e.g., Panama; Cedergren \& Sankoff, 1975). Most notably, there is no evidence that any dialect of Spanish categorically weakens the nasal consonant (the path of development observed in Romance languages with nasal vowel phonemes, like French). In addition to regional differences, nasal consonant weakening (be it velarization or deletion) has also been shown to be susceptible to language-internal and -external pressures. Weakening appears to be more prevalent word-finally than word-internally (Haché de Yunén, 1981, specifically for Dominican Spanish). The surrounding segments likewise contribute to variation, though findings are mixed. Some researchers report that in assimilatory contexts (i.e., pre-consonantal) nasal consonant effacement (and nasalization) is more frequent. Others have reported that non-assimilatory environments (pre-pausal and pre-vocalic) favor weakening: Pre-pausal has been reported to be another favoring environment for nasal consonant deletion, and pre-vocalic, for velarization (Cedergren \& Sankoff, 1975; D’Introno \& Sosa, 1988; Haché de Yunén, 1981; López Morales, 1980; Terrell, 1975). ${ }^{3}$ Among social factors, age, sex, socio-economic status, urban versus rural origin, and in contact versus non-contact with [n]-dialects have been identified as predictors for

\footnotetext{
2 Also the view for Asturian, another Romance language, that also exhibits word-final nasal velarization (Cadierno \& Prieto, 1991).

3 The above observations are primarily based on research examining Caribbean [n]-dialects. Other [n]-dialects have not been studied in such depth. A priori, I do not suspect reasons to expect different observations other [n]-dialects, though I do not discard the possibility.
} 
velarization and nasal consonant deletion (Cedergren \& Sankoff, 1975; Haché de Yunén, 1981; Hernández, 2009).

Recent instrumental research has garnered support for the (impressionistic) observations of $/ \mathrm{n} /$ weakening and anticipatory vowel nasalization in [ $\mathrm{\eta}]$-dialects. An asset of this work has been the comparison of different [y]-[n]-dialect pairs (e.g., Galician versus Castilian Spanish, Ramsammy, 2011, 2013; Cuban versus Argentine Spanish, Colantoni \& Kochetov, 2012; Kochetov \& Colantoni, 2011; Cuban versus Peninsular Spanish, Lederer, 2000 cited in Lederer, 2003). In addition to confirming the more back articulation, electropalatographic studies have also shown that, among speakers of [ $\mathrm{\eta}$ ]-dialects, nasal consonants were less constricted compared to their [n]-dialect counterpart, to the point that the nasal consonant was conjectured as [ũ]] (Colantoni \& Kochetov, 2012; Ramsammy, 2011, 2013). One area in which EPG findings challenge earlier descriptions relates to assimilation in place of articulation. Though the previous accounts describe [y]-dialects as resilient to assimilation (i.e., [ $\mathrm{y}$ ] is preferred even when adjacent to a non-dorsal nasal), EPG measurements show that [y]-dialects do in fact exhibit assimilation of place features, at least when adjacent to voiceless stops (Kochetov \& Colantoni, 2011; Ramsammy, 2011, 2013).

Regarding anticipatory vowel nasalization, instrumental research has shown that [n]-dialects of Spanish exhibit earlier onset of nasalization compared to [n]-dialects. Lederer (2000, cited in Lederer, 2003) anchors her comparison of Cuban and Peninsular Spanish in Solé (1992) (see next section), who shows that the phonetic underpinnings of phonetic/coarticulatory (Peninsular Spanish) and phonologized (American English) nasalization are different. Much like American English, Cuban Spanish exhibited earlier onset of nasalization than Peninsular Spanish. Based on these patterns, the author concluded that anticipatory nasalization was an intended feature of the pre-nasal vowel for Cuban Spanish, but the mechanical by-product of coarticulation in the Peninsular dialect (Lederer, 2003).

With the previous research as a backdrop, in Bongiovanni (2021), I analyzed the time course of nasalization in Santo Domingo and Buenos Aires Spanish to test the phonetic underpinnings of anticipatory vowel nasalization in an [n]- and an [n]-dialect, respectively. Findings revealed that onset of nasalization was earlier for Santo Domingo than for Buenos Aires Spanish. The study also examined the effect of several linguistic variables (vowel type, stress, prosodic environment, in consonance with phonetics and historical sources), of which two are particularly relevant to the present study. Firstly, the effect of stress was only significant for Santo Domingo. Given that stress typically magnifies cues that encode a linguistic distinction, this last finding was interpreted as a potential indicator of phonologized nasalization for the [y]-dialect. Second, two prosodic environments-expected to lead to greater and lesser consonantal weakening, prevocalic versus utterance final-were compared. Earlier onset of nasalization was found in the pre-vocalic environment across dialect groups, suggesting a covariation effect. One drawback 
from this study, however, was that it only examined the time-course of nasalization. In this article, I return to the same corpus, but examine nasal consonant weakening and, crucially, covariation between $/ \mathrm{n} /$ weakening and anticipatory vowel nasalization. In Section 3, I expand on how the studies differ.

Taken together, a fair assumption is that Spanish dialectal differences in nasalization ought to be primarily one of nasal consonant weakening. Yet, despite the congruence of evidence from formal, sociolinguistic and phonetic research, instrumental studies examining covariation between nasal consonant and nasalization in Spanish are lacking (understandably, given the methodological restrictions of EPG and nasography). This study employs a nasometer, a device that allows to accurately examine nasality together with consonant weakening. Prior to detailing the methods of inquiry, the next section reviews literature on the trading relationship of $/ \mathrm{n}$ / weakening and nasalization outside of Hispanic linguistics.

\subsection{Covariation between $/ \mathrm{n} /$ weakening and anticipatory vowel nasalization beyond Spanish}

The relationship between weakening of the nasal consonant and anticipatory vowel nasalization has long been theorized about and probed via experimental techniques (e.g., Beddor, 2009; Hajek, 1997; Ohala \& Ohala, 1993; Sampson, 1999; Trigo, 1988; Zhang, 2000). Much like in the Hispanic linguistics literature, backing of the nasal consonant emerges as a reflex of $/ \mathrm{n}$ / attenuation. For example, drawing from data on Mandarin dialects, Chen (1973) and Ruhlen (1973, p. 12), posit that all final nasal consonants gradually merge to [ $\mathrm{y}]$ before they are fully elided and the pre-nasal vowel fully nasalized. Another view is proposed in Trigo (1988), where $[\mathrm{y}]$ is a representation of a place-less consonantal segment that surfaces in order to interpret an underlying [ + consonant] feature (see also Rice, 1996), in contrast to a nasalized glide (e.g. [ũ]]) which surfaces when there is no consonantal feature. More recent instrumental research indeed shows that in languages with velarized word-final nasals (whether phonemic or variants of a phoneme), these are typically less constricted than their alveolar counterparts (e.g., Colantoni \& Kochetov, 2012; Ramsammy, 2013; Zhang, 2000), and often misperceived as nasal vowels (Ohala \& Ohala, 1993; Zhang, 2000). Thus, the phonetic basis for a relationship between backing and nasal consonant weakening, and their relationship to vowel nasalization, is well-attested.

The role of temporal reduction in the trading relationship has also been noted (e.g., Chen, 1973; Foley, 1975). Production data from a number of languages supports the view that the timing of vowel nasalization is the result of earlier or later onset of a roughly constant-sized nasal gesture relative to tongue-tip raising for $/ \mathrm{n} /$, instead of an increase or decrease in nasalization per se (e.g., English, Italian, Japanese, and Thai; Beddor, 2007, 2009; Busà, 2003; Hattori, Yamamoto, \& Fujimura, 1958; Onsuwan, 2005). Perception research also supports this view. Beddor (2012) shows that the more extensive nasalization is in the pre-nasal vowel, the shorter [n] is required 
to elicit /n/ responses (i.e., listeners identifying the stimulus as bend versus bed). On the whole, this literature underscores the role of covariation between nasal consonant weakening and nasalization as a precursor to phonologization of nasalization in the pre-nasal vowel, be it a nasal vowel phoneme (such as in French, lot 'prize' /lo/ [lo] versus long 'long' [lõ]) or a nasalized vowel (like in pre-nasal vowels in English, e.g., ban /bæn/ [bæ̃n] versus bad /bæd/ [bæd]).

Another set of findings in the phonetics literature regarding vowel nasalization is relevant here. Sub-phonemic nasalization can be an intrinsic effect of the speech mechanism, or it can be a specified feature of a pre-nasal vowel. Evidence for this dichotomy can be found in Solé (1992, 1995). Drawing from nasographic data on English and Peninsular Spanish, Solé (1992) shows that, for Spanish, nasal airflow in the pre-nasal vowel remains low for most of its duration and ramps up at the time of the articulatory closure. For English, on the other hand, anticipatory nasalization is aligned with onset of the vowel, and so it starts earlier in the pre-nasal vowel. Based on these findings, the author proposed that in the case of (Peninsular) Spanish, nasalization in the pre-nasal vowel represents a low-level motor adjustment (i.e., phonetic or coarticulatory), whereas for English, the gestural retiming constitutes a higher-level adjustment (phonologized; see also Cohn, 1993; Sampson, 1999).

The above observations have implications for Spanish phonology. A priori, the evidence above suggests that [n]-dialects would be just as susceptible to covariation pressures. At the same time, dialectal differences in the time-course of nasalization have been documented (Lederer, 2000, cited in Lederer, 2003; Bongiovanni, 2021). If the differences in the timing of nasalization are purely the result of nasal consonant weakening, one would expect an [n]-dialect to exhibit greater nasal consonant weakening than an [n]-dialect. But, if dialectal differences are akin to Solé's (1992, 1995) distinction between low- and high-level nasalization (or, phonetic or coarticulatory versus phonologized), as documented in Lederer (2000, cited in Lederer, 2003) and Bongiovanni (2021), variable vowel nasalization may not be fully ascribed to $/ \mathrm{n} /$ attenuation. This scenario raises the genuine possibility that, at least for the [n]-dialect, nasalization is not a marker of nasal consonant weakening, but an intended feature of the vowel in and of itself. Is it possible that at similar degrees of nasal consonant weakening, an [y]- dialect still exhibits earlier onset of nasalization compared to an [n]-dialect? Dialectal differences in Spanish provide new testing grounds for predictions regarding covariation between $/ \mathrm{n} /$ weakening and anticipatory vowel nasalization. The next section details the methods of inquiry.

\section{Methods}

The core issue this article seeks to address relates to dialectal differences in the trade off between nasal consonant weakening and nasalization. In light of the literature above, a number of possible scenarios regarding /n/ weakening and anticipatory vowel nasalization for [n]- and [y]-dialects of Spanish are conceivable. Bongiovanni (2021) showed that the [n]-dialect under 
study exhibited earlier onset of nasalization across a number of conditions. So, it is likely that Santo Domingo Spanish exhibits greater consonant weakening as well. But, if /n/ attenuation is equal or greater for Buenos Aires Spanish, then the greater extent of nasalization cannot be fully ascribed to nasal consonant weakening.

In order to address this set of predictions, the present study returns to the corpus in Bongiovanni (2021) but diverges from the previous study in at least two important ways. While Bongiovanni (2021) aimed at documenting dialectal patterns of anticipatory vowel nasalization, the present study focuses on the trading relationship between nasal consonant weakening and nasalization, and therefore, incorporates the examination of word-final $/ \mathrm{n} /$. Regarding the controlled phonological variables, the present study exclusively examines pre-consonantal environments (see below), whereas Bongiovanni (2021) examined word-final nasals preceding a vowel or a pause. As such, the present analysis incorporates data that has not been examined previously. In doing so, it further probes phonetic differences in nasalization across dialects of Spanish.

\subsection{Research locale, speakers, and equipment}

Buenos Aires and Santo Domingo Spanish were chosen for several reasons. First, among [y]-dialects, Santo Domingo Spanish occupies an intermediate place between dialects with the highest tendency towards nasal consonant effacement (Panama Spanish, Cedergren \& Sankoff, 1975) and the lowest (Puerto Rico Spanish, López Morales, 1980). Among [n]-dialects, Buenos Aires Spanish is not in contact with any [n]-dialect (unlike other well-known [n]-dialects, such as varieties in the Iberian Peninsula). Finally, the broader regional context was also taken into consideration. Both Santo Domingo and Buenos Aires constitute the cultural, financial, political, and commercial centers within their regions (though not necessarily the only ones). Of course, there are territorial and population number differences between the cities, but the above similarities render them comparable research locales.

Participants were 28 native speakers of Santo Domingo Spanish (aged 18-27 years old; 18 women and 10 men) and 26 speakers of Buenos Aires Spanish (aged 19-28 years old; 18 women and 8 men), recorded within their dialectal region. ${ }^{4}$ Instead of a traditional microphone, pronunciations were recorded with a nasometer (Glottal Enterprises NAS-1 SEP Clinic), a split channel set of microphones separated by a removable plate, that records oral and nasal signals simultaneously yet separately. Recordings were done in Praat (Boersma \& Weenink, 2016), in stereo, and sampled at $44.1 \mathrm{kHz}$.

\footnotetext{
${ }^{4}$ The analysis was restricted to college students in order to control for age and educational background and allow comparability across dialect groups as much as possible. Future research will be well served by additionally comparing across age groups within each dialect community.
} 


\subsection{Elicitation materials}

Stimuli in this study were real words, ending with a CVN syllable and, for comparison, also CVC (Note: $\mathrm{C}=$ oral consonant, $\mathrm{V}=$ vowel, and $\mathrm{N}=$ nasal consonant). The pre-nasal vowel was either a mid-vowel (/e o/) or a low vowel (/a/). No high vowels were included due to lacunae in the Spanish lexicon. Although a number of linguistic variables have been explored in previous work (e.g., vowel height, Bongiovanni, 2021; Clumeck, 1976; Krakow, 1999, among others), I focus here on two: stress and consonantal environment. Stress seeks to create conditions for weakening (e.g., unstressed versus stressed). The inclusion of the consonantal environment, on the other hand, followed two reasons. First, the dialects under study were expected to differ in the articulatory details of the 'preferred' word-final nasal (alveolar versus velar). Given that nasometry (see next subsection) does not allow the direct observation of place of articulation, it was decided to place the word-final $/ \mathrm{n} /$ in positions that would facilitate coarticulation, and thus allow for comparable environments. Second, given the documented relationship between consonant backing and greater anticipatory vowel nasalization, it was important to facilitate environments for a more fronted and a more back /n/. Thus, word-final nasal consonants were preceded by a dorsal consonant $(/ \mathrm{k} /$ in all cases) or a coronal ( $/ \mathrm{t} /$ in all cases, examples follow). For an analysis of non-assimilating environments (e.g., pre-pausal and prevocalic), see Bongiovanni (2021).

Stimuli were embedded in carrier phrases (e.g., el capitán casado 'the married captain' and el capitán tacaño 'the stingy captain'), ${ }^{5}$ displayed in Microsoft PowerPoint on the same laptop used in recording (a MacbookPro with a 13" screen). Table 1 presents sample reading items; supplementary materials include all items employed. Slides were randomized anew for each participant, and advanced automatically in order to standardize speech rate across repetitions (to the extent possible).

\begin{tabular}{lll} 
& Pre-coronal & Pre-dorsal \\
\hline Stressed & $\begin{array}{l}\text { La sartén torcida } \\
\text { 'The crooked skillet' }\end{array}$ & $\begin{array}{l}\text { La sartén caliente } \\
\text { 'The hot skillet' }\end{array}$ \\
Unstressed & $\begin{array}{l}\text { Cuando tiraron tabaco } \\
\text { 'When they threw tobacco' }\end{array}$ & $\begin{array}{l}\text { Cuando tiraron cadenas } \\
\text { 'When they threw chains' }\end{array}$
\end{tabular}

Table 1: Sample reading items.

\subsection{Annotation and instrumental analysis}

A total of 1994 ( 2 stress conditions $\times 2$ pre-consonantal conditions $\times 9$ repetitions $\times 54$ speakers) tokens were extracted. After eliminating some observations primarily due to misreading and

\footnotetext{
${ }^{5}$ This type of carrier phrase was used, instead of more 'traditional' carrier phrases of the type 'I say [target word] for you,' to avoid a repetitive and tiresome task.
} 
disfluencies, the total number of analyzed observations was 1856 ( $n=924$, for Buenos Aires; $n=932$, for Santo Domingo). Table A1 in the supplementary materials includes number of tokens per condition. Praat was used for segmentation and for measurement extraction. Figure 1

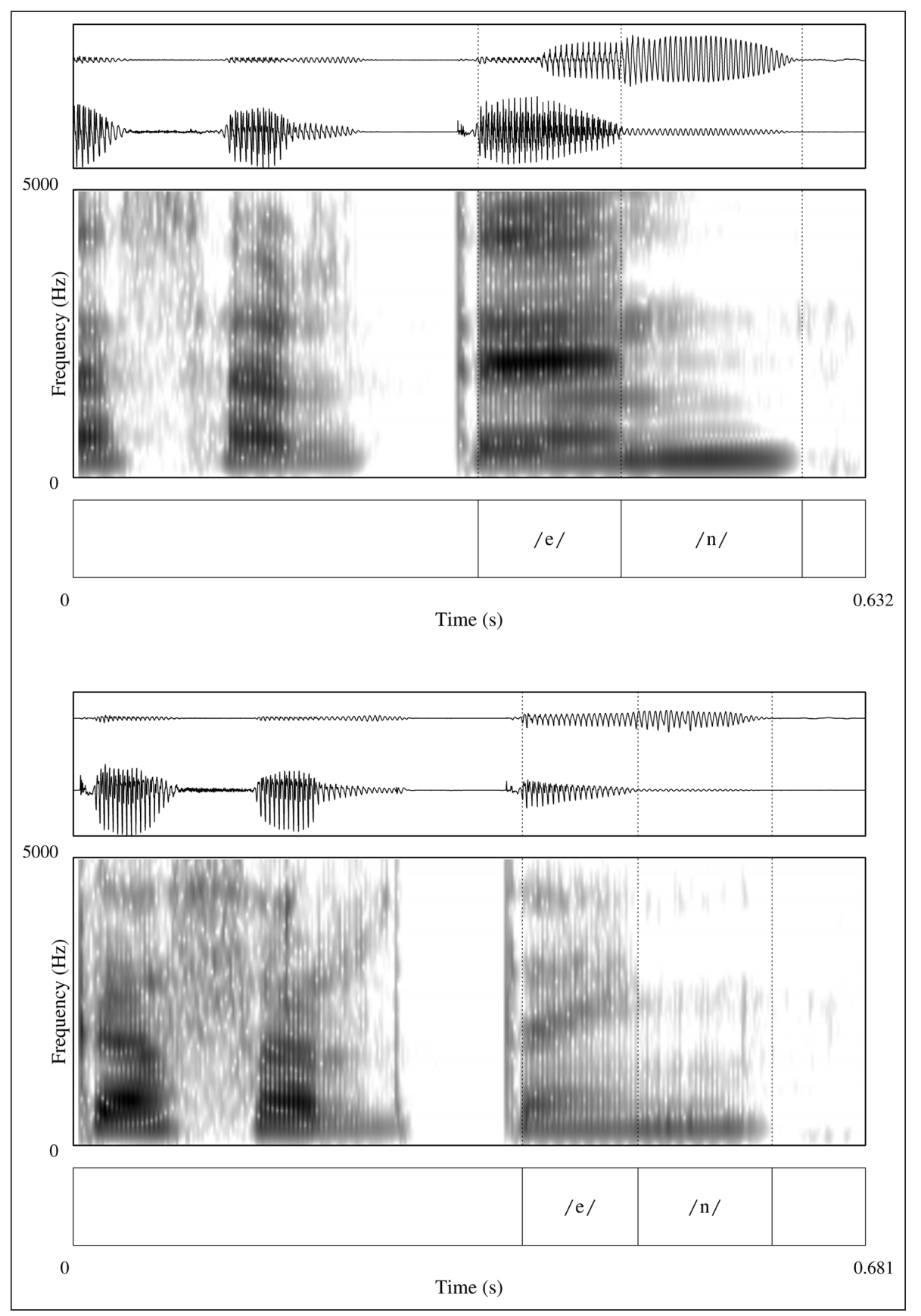

Figure 1: Waveforms and spectrograms of the word sartén 'skillet,' produced by a Buenos Aires Speaker (top) and a Santo Domingo speaker (bottom). 
presents waveforms and spectrograms of utterances by a speaker of each dialect group, showing nasal and oral channels (Channel 1 and Channel 2, respectively). The differences between channels are readily visible. For oral segments, the signal in the nasal channel remains mostly flat over the course of the segment. As the nasal consonant approaches, the signal in the nasal channel increases while the one in the oral channel decreases, thus indicating airflow through the nose and a constriction in the oral cavity.

For segmentation purposes, a sudden absence of audio in the oral channel waveform and a strong presence of audio in the nasal channel one was taken as an index of the nasal segment. Spectrographic reading also provided relevant information, such as the visual presence of an abrupt change and damping of formant frequencies, as well as the presence of antiformants, at the time of the formation of the articulatory closure (see below for how cases with no visible oral occlusions were handled).

Two acoustic measurements were extracted automatically with Praat scripts. The first measurement was duration of the consonant, in milliseconds. Second, amplitude (i.e., sound pressure energy), in both oral and nasal channels, was extracted at 20 equidistant time-points over the course of the word-final consonant (e.g., /n/) and of its preceding vowel (e.g., /e/). For cases with no visible occlusion, duration was established at zero and measurements of energy were only taken during the pre-nasal vowel. Because the amplitude signal exhibited jitter, they were smoothed using a 5-point window prior to analysis.

Temporal and amplitude measurements were used to characterize nasal consonant weakening and anticipatory vowel nasalization. Following work by Beddor (e.g., Beddor, 2009), weakening of the nasal consonant was examined in terms of segmental duration (i.e., shorter nasals are more lenited). Additionally, much like the characterization of weakening of Spanish /b d g/ (e.g., Hualde, Simonet, \& Nadeu, 2011), an acoustic index of degree of constriction was also employed (i.e., less constricted nasals are more weakened). Since the presence of energy in the oral channel indicates airflow through oral cavity, constricted segments, such as a consonant, should exhibit lesser amplitude in the oral signal compared to an unconstricted segment, like a vowel. For this purpose, the ratio of oral energy in the nasal consonant (i.e., a constricted segment) to oral energy in the pre-nasal vowel (i.e., an unconstricted segment) was calculated, henceforth 'consonant-to-vowel energy ratio.' Anticipatory vowel nasalization, on the other hand, was characterized in terms of the time-course of nasality. Nasal energy was treated as a proxy for the velic gesture-a higher index of energy indicates airflow through the nasal cavity and therefore a lowered velum. With methodologies such as airflow and EMMA as a model (Delvaux, Demolin, Harmegnies, \& Soquet, 2008; Honorof, 1999; Solé, 1992), first, the minimum and the maximum energy were located for each token, during the span of the vowel-nasal sequence. Next, the range between the two was calculated. Onset of the nasalization was operationalized as the point at which nasal energy crossed a threshold of $15 \%$ of the range. 


\section{Results}

\subsection{Control items}

CVC syllables are not expected to present evidence of nasality, neither in the consonant nor in the tautosyllabic vowel (see Figure 2). CVC syllables do not include a velic gesture and, therefore, presented floor-level readings of amplitude of nasal traces. On the other hand, syllables with a word-final nasal consonant showed traces of increasing nasal energy. These data confirm the proper functioning of the nasometer. Since there is no velic movement during CVC syllables, control items will not be considered further.

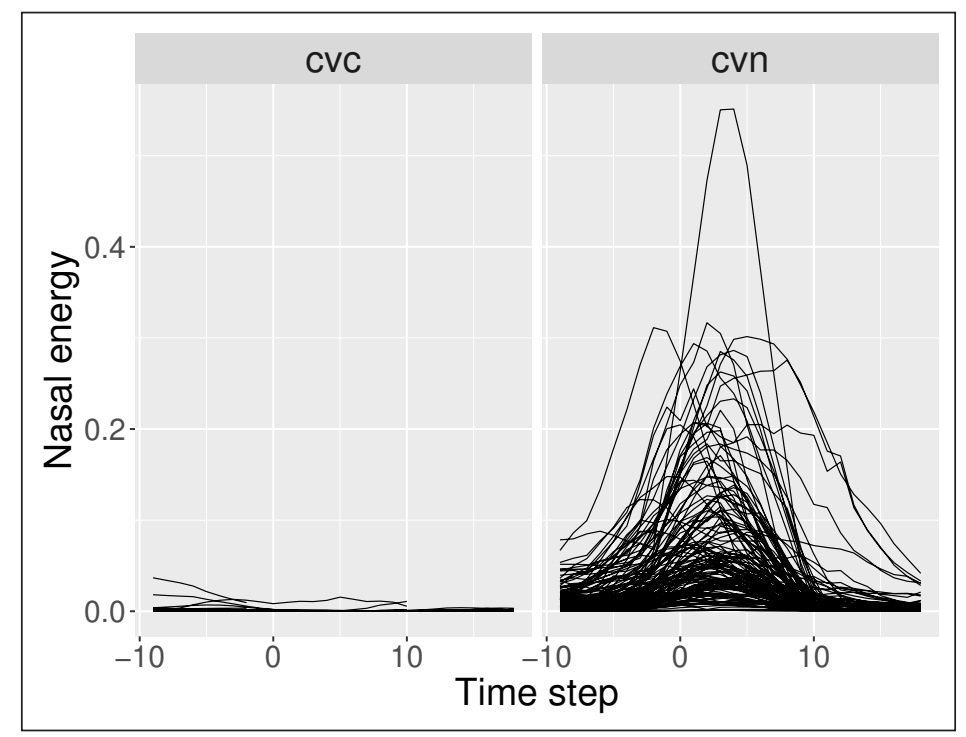

Figure 2: Time-course of nasal energy during pre-nasal vowel in CVC and CVN in 250 randomly selected tokens. The zero time-point corresponds with vowel-consonant boundary.

\subsection{Covariation}

I start the results section by bringing forward the crucial analysis: covariation between nasal consonant and onset of anticipatory vowel nasalization. All visualization and statistical modeling in this article were done in R (R Core Team, 2019), using the tidyverse suite of packages (Wickham et al., 2019) and the lmer() function from the 'lme4' package (Bates, Mächler, Bolker, \& Walker, 2015). Prior to performing the analyses, duration was standardized using the scale function (Winter, 2019).

Visual inspection of the data revealed the same trend for both acoustic measurements of nasal consonant weakening: As the nasal consonant weakens (decreases in duration or increases in consonant-to-vowel energy ratio), onset of nasalization starts earlier (Figure 3). The effect was similar across dialects, though the temporal effect appears to be greater for Buenos Aires Spanish (circles, dashed lines), as evidenced by a steeper trend. A possible interpretation for this 


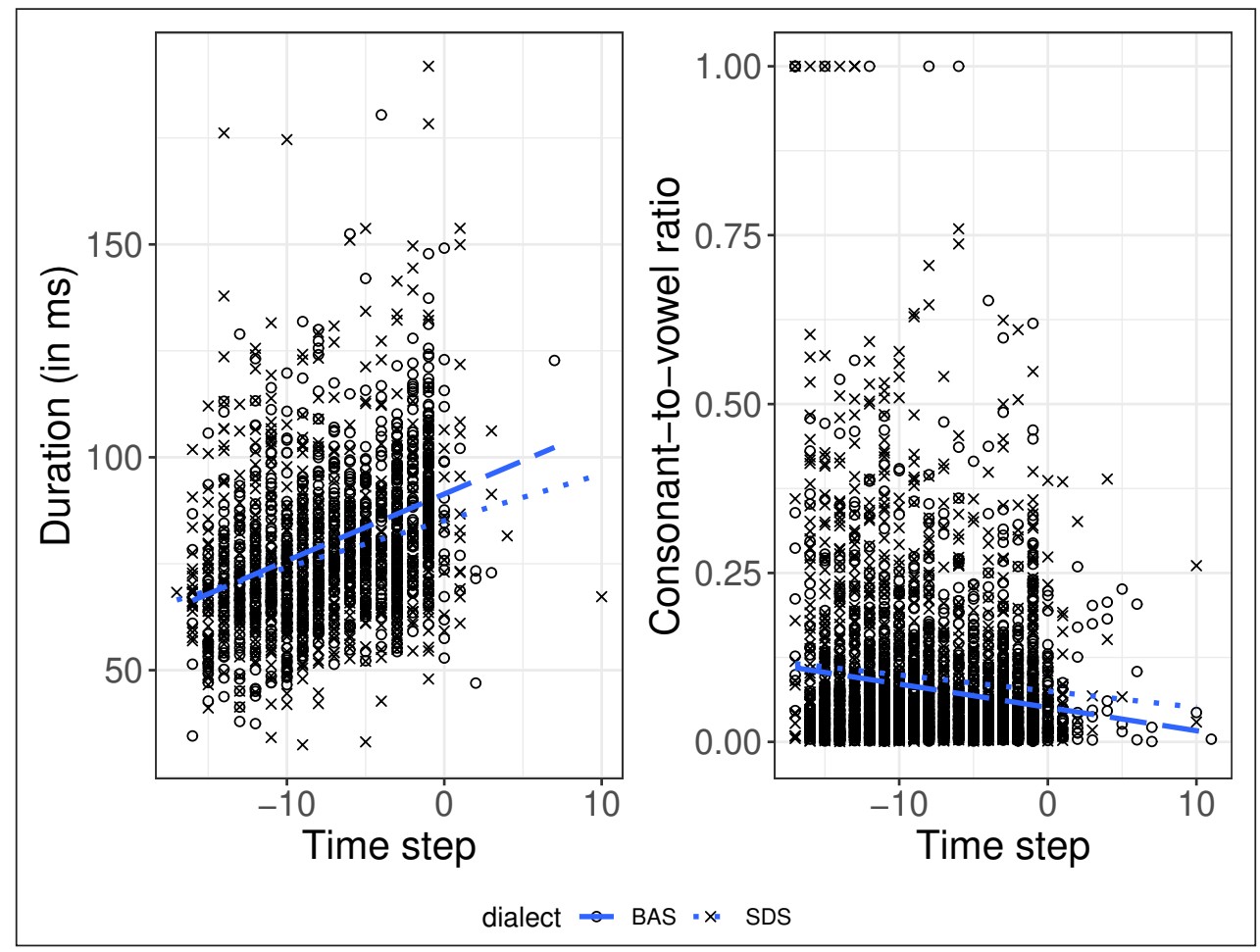

Figure 3: Onset of velum lowering as a function of duration of the nasal consonant (left) and consonant-to-vowel energy ratio (right), per dialect. The zero time-point corresponds with vowel-nasal boundary. Trend lines were generated by means of stat_smooth(), with an argument of method $=$ 'lm.'

finding is that duration is more sensitive as a measurement and thus captures more fine-grained acoustic detail. Or, that regardless of duration, constriction of the nasal consonant is comparable across dialects, though slightly more weakened for Santo Domingo in this formal speech task. All in all, the trend of earlier onset of nasalization with more weakened nasal consonants is observable for the [n]-dialect as much as for the [n]-dialect.

To test whether the relationship between nasal consonant weakening and the time-course of nasalization was statistically significant, a mixed effects linear regression model was run with the lmer() function ('lme4' package, Bates et al., 2015). Time step of onset of nasalization was entered as dependent variable, and nasal consonant duration, consonant-to-vowel energy ratio, and dialect group as fixed effects, with by-speaker and by-word random intercepts. Interaction terms between the acoustic measurements and dialect group were also included in the model. Buenos Aires was the reference level; therefore, the intercept term refers to this dialect group. Statistical significance was set at $\alpha=.05$. The results are summarized in Table 2. All main effects were statistically significant, as were the interaction terms. Results follow the trends visually captured during data inspection: Earlier onset of nasalization obtains (a) when the nasal consonant is shorter, (b) less constricted, and (c) in Santo Domingo Spanish. 


\begin{tabular}{llllll} 
Fixed effect & Estimate & $\boldsymbol{S E}$ & df & $\boldsymbol{t}$-value & $\boldsymbol{p}$ \\
\hline (Intercept) & -6.59 & 0.62 & 16.99 & 10.64 & $<0.001$ \\
Duration & 2.14 & 0.16 & 1791.11 & 13.52 & $<0.001$ \\
Energy ratio & -4.37 & 2.03 & 1831.50 & -2.15 & $<0.05$ \\
Santo Domingo & -1.71 & 0.60 & 61.24 & -2.84 & $<0.01$ \\
Duration*Santo Domingo & -1.09 & 0.21 & 1820.43 & -5.28 & $<0.001$ \\
Energy ratio*Santo Domingo & 10.89 & 2.79 & 1831.05 & 3.91 & $<0.001$
\end{tabular}

Table 2: Mixed effects linear regression model for covariation.

\subsection{Nasal consonant weakening}

An initial inspection of the results showed extensive acoustic overlap, evident in the almost identical violin plots (Figure 4). Santo Domingo $/ \mathrm{n} /$ is only minimally longer than that of Buenos Aires. Mean duration of the word-final nasal consonant is $76.3 \mathrm{~ms}(S D=19.1)$ for this dialect group, compared to Buenos Aires, with a mean of $81 \mathrm{~ms}(S D=18)$. Notably, the data also exhibits a pervasive lack of nasal consonant weakening (regardless of dialect). Particularly for consonant-to-vowel energy ratio, the data cluster at zero, ${ }^{6}$ the value that signals that the

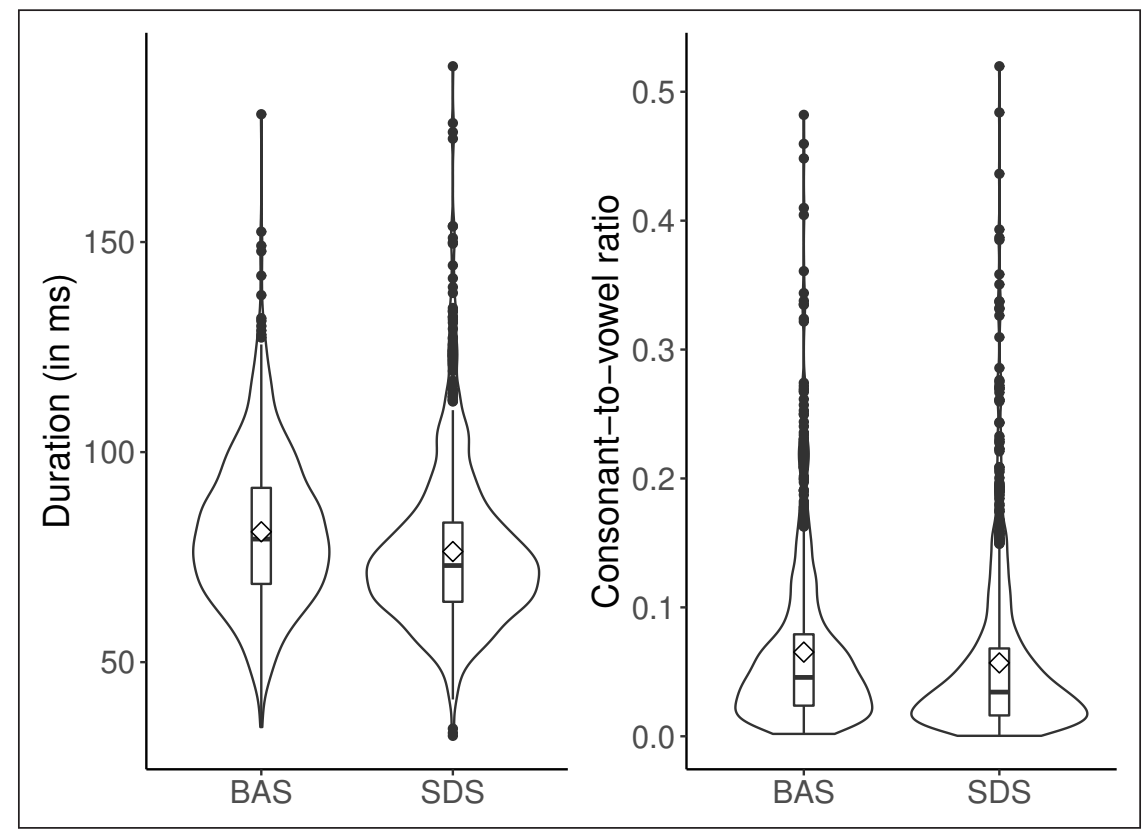

Figure 4: Duration of the nasal consonant (left) and consonant-to-vowel energy ratio (right), per dialect group. Diamonds represent the mean.

\footnotetext{
${ }^{6}$ These data were also examined as rationalized arcsine transform units (Studebaker, 1985), but it did not show a more normal distribution either.
} 
nasal is most consonant-like, or constricted. The fact that the Santo Domingo group exhibits low degree of weakening, as indexed by the two acoustic measurements, is an unexpected finding considering the impressionistic observations in previous research. The acoustic overlap between dialects was not predicted based on earlier literature either. See Section 5 for a discussion of this finding.

Inspection of the independent variables revealed acoustic overlap among their respective levels as well. Nevertheless, some patterns could be teased apart. Starting with stress, unstressed syllables presented a higher degree of consonantal weakening, with shorter durations and higher consonant-to-vowel energy ratio (Figure 5). With regard to pre-consonantal environments (where the word-final nasal is expected to assimilate to place of articulation of the acrossboundary consonant), nasals were more weakened (i.e., shorter duration and higher consonantto-vowel energy ratio) in the pre-dorsal than in the pre-coronal environment (Figure 6). This finding parallels previous results of more weakened velar nasals (when compared to coronal counterparts; Ramsammy, 2011; Zhang, 2000). In all cases, Santo Domingo Spanish exhibited greater consonantal weakening, but only very slightly.

To test the statistical significance of these patterns both acoustic measurements of weakening were analyzed using mixed effects linear regression models, one for each measurement. Duration

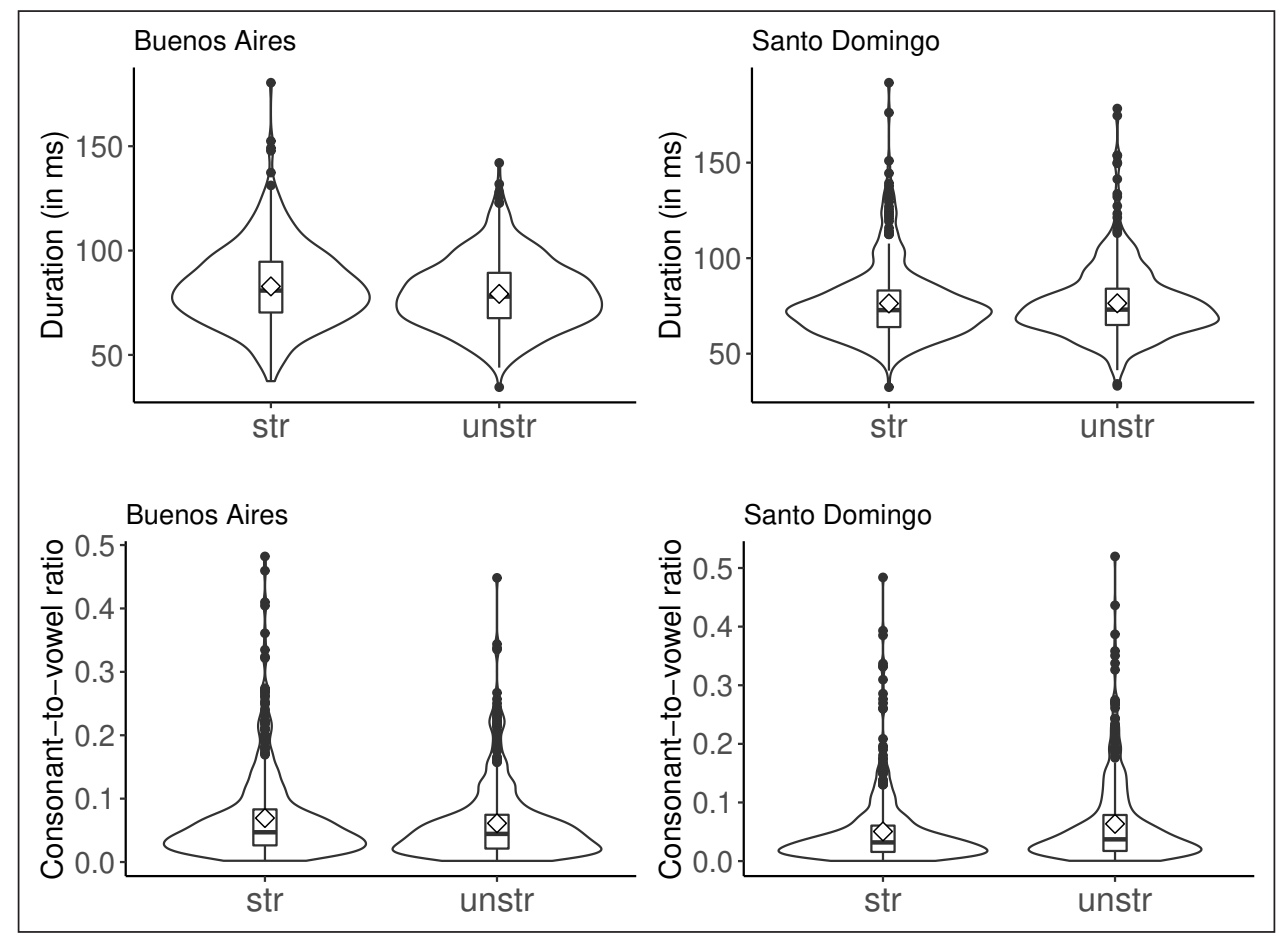

Figure 5: Duration of the nasal consonant (top) and consonant-to-vowel energy ratio (bottom), per stress condition and dialect group. Diamonds represent the mean. 


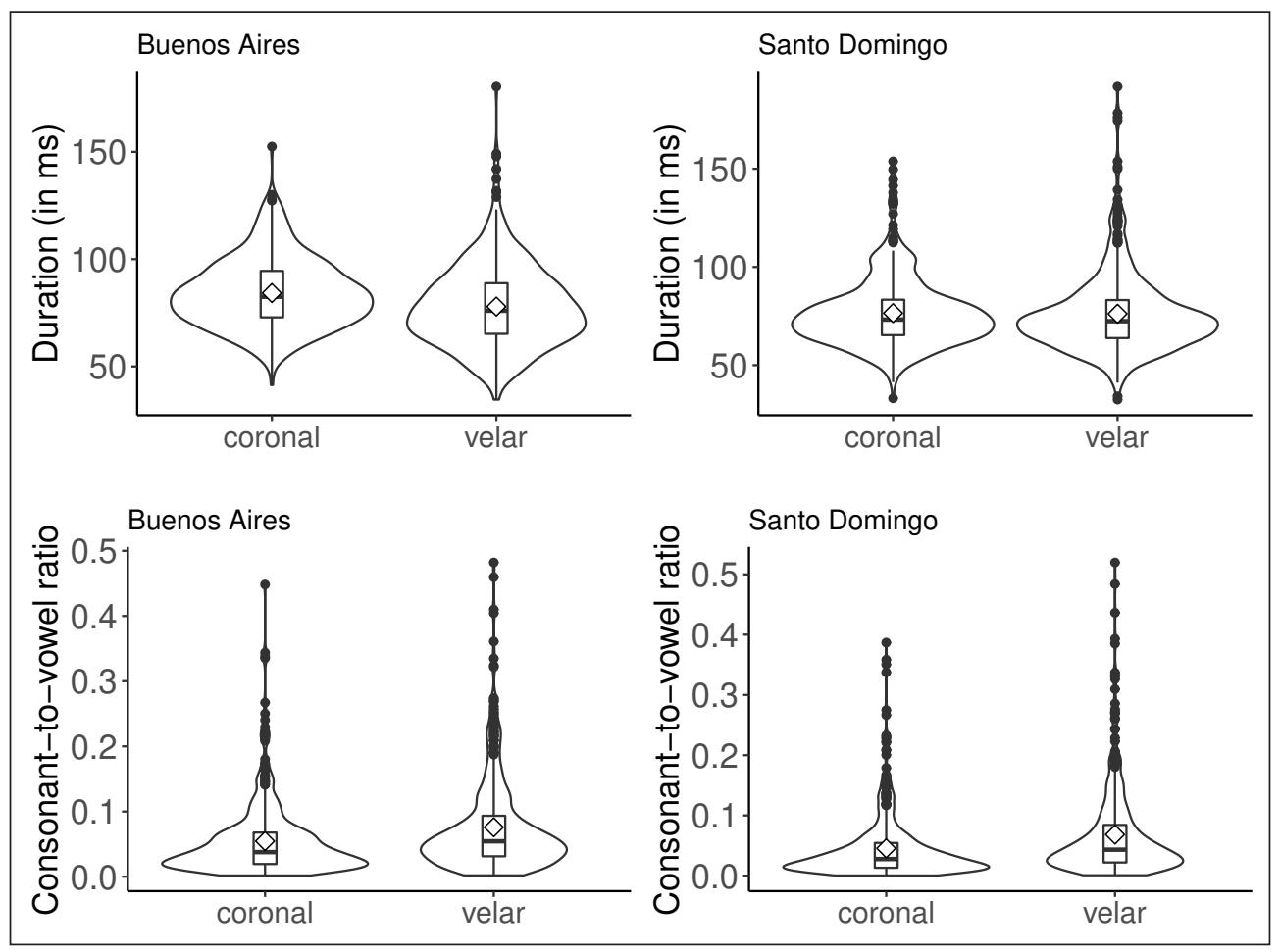

Figure 6: Duration of the nasal consonant (top) and consonant-to-vowel energy ratio (bottom), per environment condition and dialect group. Diamonds represent the mean.

of the nasal consonant and consonant-to-vowel energy ratio were entered into their respective model as the dependent variable. Dialect group, stress condition, and environment were included as fixed effects, and there were by-speaker and by-word random intercepts. The models included stress by dialect group and environment by dialect interaction terms. Statistical significance was also set at $\alpha=.05$. For both models, the baseline is Buenos Aires stressed and pre-coronal environments. Therefore, this is the intercept (Tables 3 and 4).

In Table 3, the model for duration showed a statistical fixed effect for dialect group and pre-consonantal environment; stress was not significant. All interaction terms were significant as well. Of note is that the direction of effects was in the expected trend, based on the previous literature and the visual inspection above. With Santo Domingo Spanish, duration of the word-final nasal decreases (i.e., greater weakening), compared to Buenos Aires Spanish. The same trend is observed for the pre-dorsal environment. The statistical interaction terms of stress by dialect and environment by dialect showed that with unstressed and with predorsal environment Santo Domingo /n/ increased in duration (i.e., less weakened). The observed effect with the Santo Domingo pre-dorsal nasals could be the result of a more back articulation (i.e., greater tongue displacement leads to longer duration). Regarding the interaction of stress by dialect, I do not have an explanation for longer duration for 


\begin{tabular}{llllll} 
Fixed effects & Estimate & $\boldsymbol{S E}$ & $\mathbf{d f}$ & $\boldsymbol{t}$-value & $\boldsymbol{p}$ \\
\hline (Intercept) & 85.95 & 2.94 & 18.14 & 29.27 & $<0.001$ \\
Dialect Santo Domingo & -9.87 & 3.12 & 64.06 & -3.16 & $<0.01$ \\
Stress unstressed & -3.60 & 2.86 & 4.52 & -1.26 & .3 \\
Environment velar & -6.23 & 0.98 & 1787.25 & -6.33 & $<0.001$ \\
Santo Domingo*unstressed & 3.67 & 1.39 & 1787.39 & 2.64 & $<0.01$ \\
Santo Domingo*velar & 6.00 & 1.39 & 1787.36 & 4.32 & $<0.001$
\end{tabular}

Table 3: Mixed effects linear regression model for duration of the nasal consonant.

\begin{tabular}{llllll} 
Fixed effect & Estimate & $\boldsymbol{S E}$ & $\mathbf{d f}$ & $\boldsymbol{t}$-value & $\boldsymbol{p}$ \\
\hline (Intercept) & 0.06 & 0.02 & $5.097 \mathrm{e}+00$ & 3.51 & $<0.05$ \\
Santo Domingo & -0.02 & 0.01 & $7.905 \mathrm{e}+01$ & -2.28 & $<0.05$ \\
Stress unstressed & -0.01 & 0.02 & $4.107 \mathrm{e}+00$ & -0.39 & 0.72 \\
Environment velar & 0.02 & 0.00 & $1.794 \mathrm{e}+03$ & 5.92 & $<0.001$ \\
Santo Domingo*unstressed & 0.02 & 0.01 & $1.795 \mathrm{e}+03$ & 4.15 & $<0.001$ \\
Santo Domingo*velar & 0.00 & 0.01 & $1.795 \mathrm{e}+03$ & 0.26 & 0.79
\end{tabular}

Table 4: Mixed effects linear regression model for consonant-to-vowel energy ratio.

unstressed Santo Domingo nasals and I am hesitant to offer one until replication of this finding is achieved.

With regard to consonant-to-vowel energy ratio (Table 4), the regression model showed a statistical fixed effect for dialect group and pre-consonantal environment. The direction of significant fixed effects was not in the expected direction. Compared to the base line of Buenos Aires, Santo Domingo showed less weakened nasal consonants, as indicated by a negative ratio number (i.e., more-consonant like). The velar environment also showed a negative trend, compared to the pre-coronal environment. The expected trends for these two effects were rooted in (a) the assumed place of articulation of the nasal consonant (velar for Santo Domingo and in pre-velar environment due to place assimilation) and (b) the documented pattern of [y] exhibiting greater weakening in general. However, this study does not test nasal place articulation. Thus, I cannot discard the possibility that $/ \mathrm{n} /$ was not in fact articulated as [n]; I discuss this issue further in Section 5. Going back to the model in Table 4, stress was not a significant main effect, but was significant as part of the interaction with dialect group. Here, nasal consonant weakening showed an increase in consonant-to-vowel energy ratio (i.e., morevowel like) for the Santo Domingo group. In any case, all differences in consonant-to-vowel energy ratio (whether in the expected direction or not) hover around zero and are unlikely to be perceptible. 
Despite regression models unveiling unexpected trends, I would like to highlight three major findings. Firstly, the extent of acoustic overlap among dialect groups was notable. The highly constricted nasal consonants is another important result. While many comparisons exhibit statistical significance, the fact remains that Santo Domingo Spanish nasals are as weakened or as constricted as Buenos Aires Spanish. I come back to this issue in the discussion section.

\subsection{Anticipatory vowel nasalization}

Visual inspection of the data in Figure 7 shows that Santo Domingo Spanish exhibited earlier onset of nasalization, which is in agreement with the patterns in Bongiovanni (2021). Though dialect groups showed higher densities towards opposing ends of the pre-nasal vowel (early onset for Santo Domingo, late onset for Buenos Aires), Figure 7 suggests bimodal distributions. This finding may be the result of the effect of the pre-consonantal environment, which I address next.

As a reminder, the pre-consonantal environments-pre-coronal and pre-dorsal-were included to create the phonetic conditions for backing of the nasal consonant. Thus, they allow examining nasalization as a result of the (assumed) articulatory details in the word-final nasal

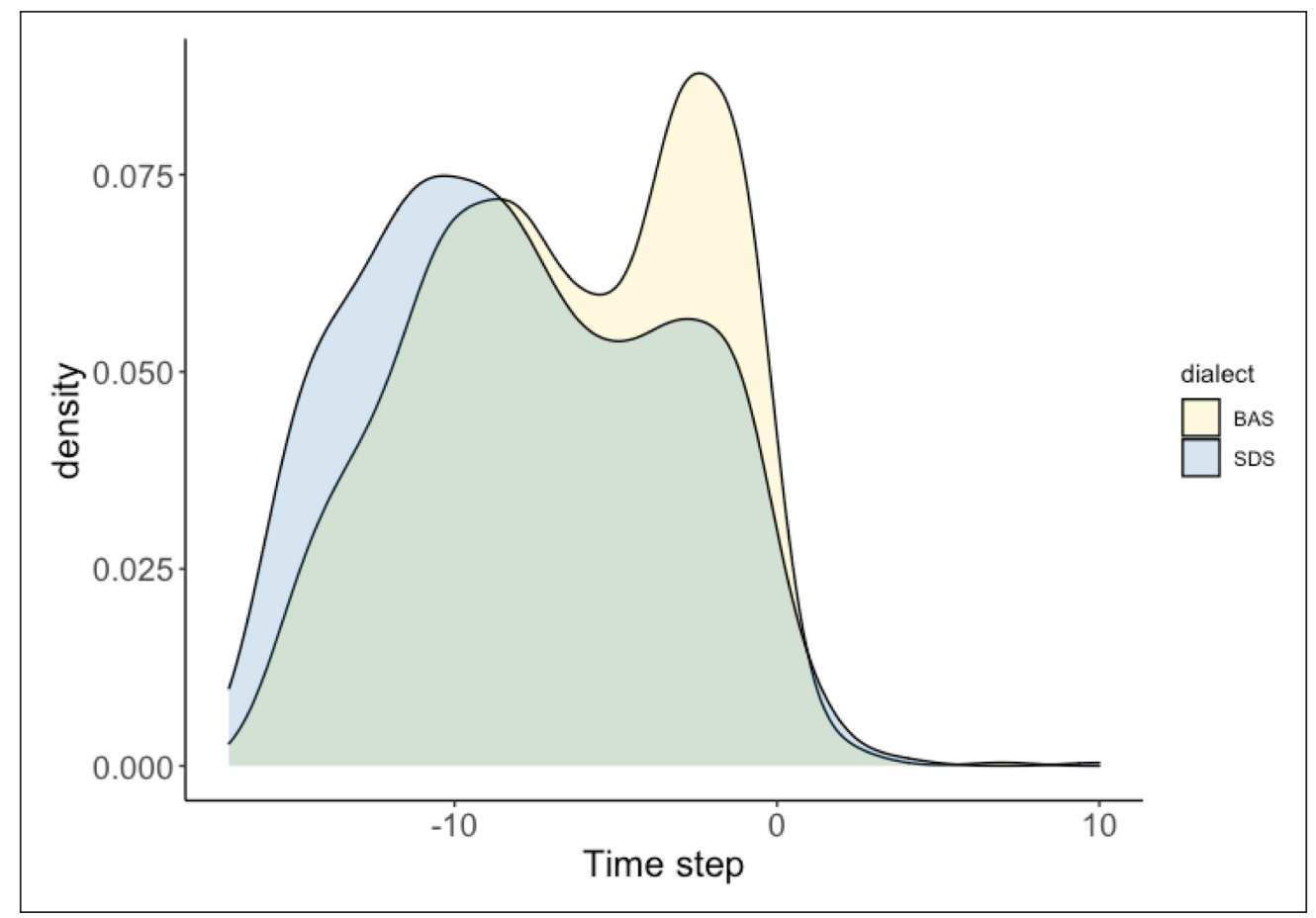

Figure 7: Onset of nasalization per dialect group. The zero time-point corresponds with vowel-nasal boundary. 


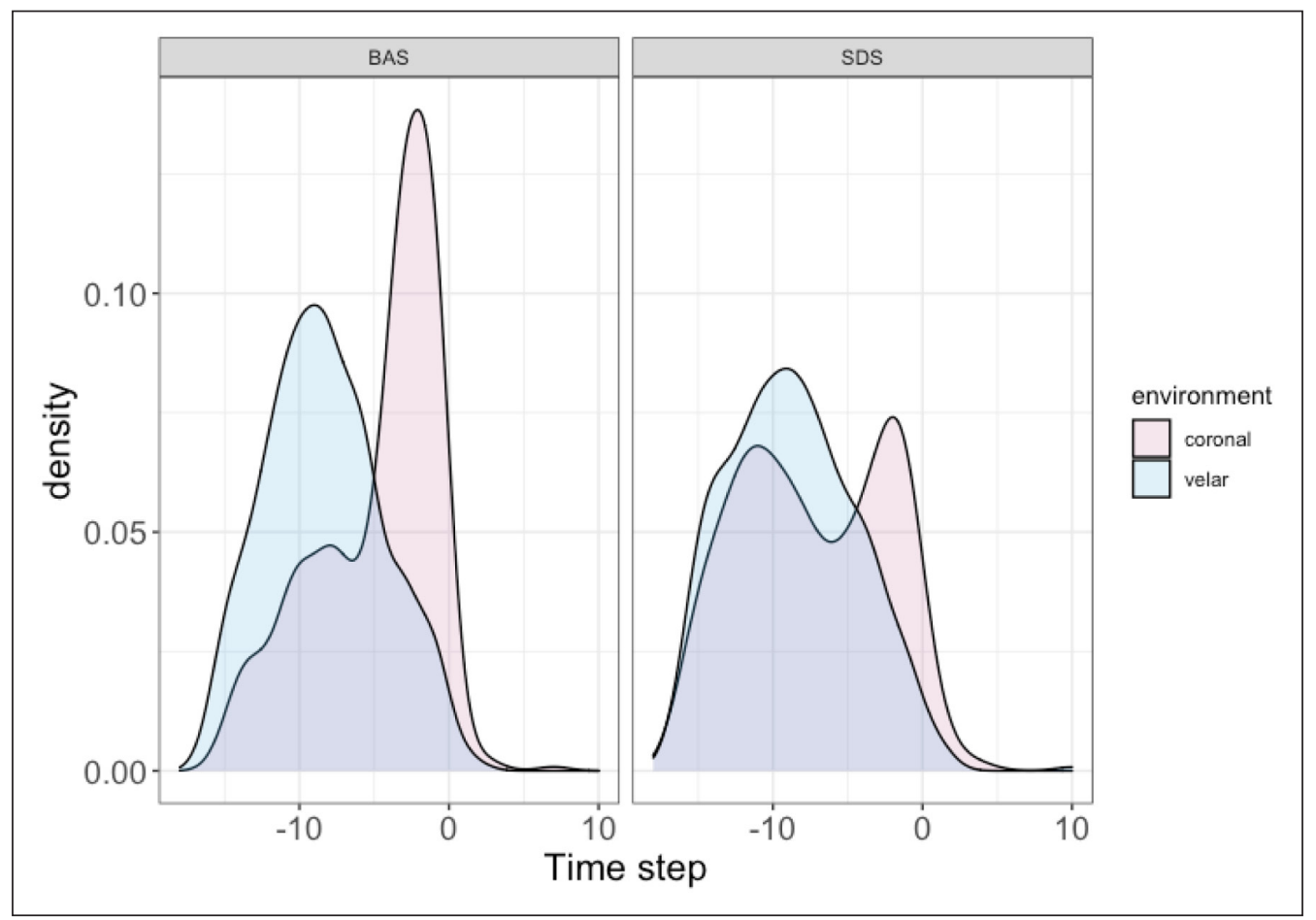

Figure 8: Onset of nasalization per environment condition and dialect group. The zero timepoint corresponds with vowel-nasal boundary.

consonant ([n] versus [ $\mathrm{y}]$ ). Visual inspection of the data per pre-consonantal environment showed that onset of nasalization took place earlier when the nasal consonant was followed by /k/ (pre-dorsal) than when followed by /t/ (pre-coronal; Figure 8).

The pre-coronal data (pink density curves) show another bimodal distribution. Upon further examination of the pre-coronal environment (for these data, see Figures A1 and A2 in the supplementary materials), it was found that, among Dominicans, at least six speakers exhibited distributions towards the left of the x-axis (early onset of nasalization; DRF01, DRF09, DRF13, DRM03, DRM04), in addition to flat distributions covering a wide range of time steps. Among Argentines, on the other hand, some speakers show a flatter distribution (BAF02, BAF14, BAF16, BAM01, BAM02, BAM05, BAM08), but none a skewed distribution. One way to account for these early onset observations is to allow for the possibility of more back articulations of $/ \mathrm{n} /$, even in the pre-coronal environment. Alternatively, regardless of the details of the nasal consonant, these speakers may routinely align nasalization with onset of the pre-nasal vowel. In either case, variation at the level of the individual may be the source for the bimodal distribution but, until examined further, I am hesitant to offer a definitive explanation. 


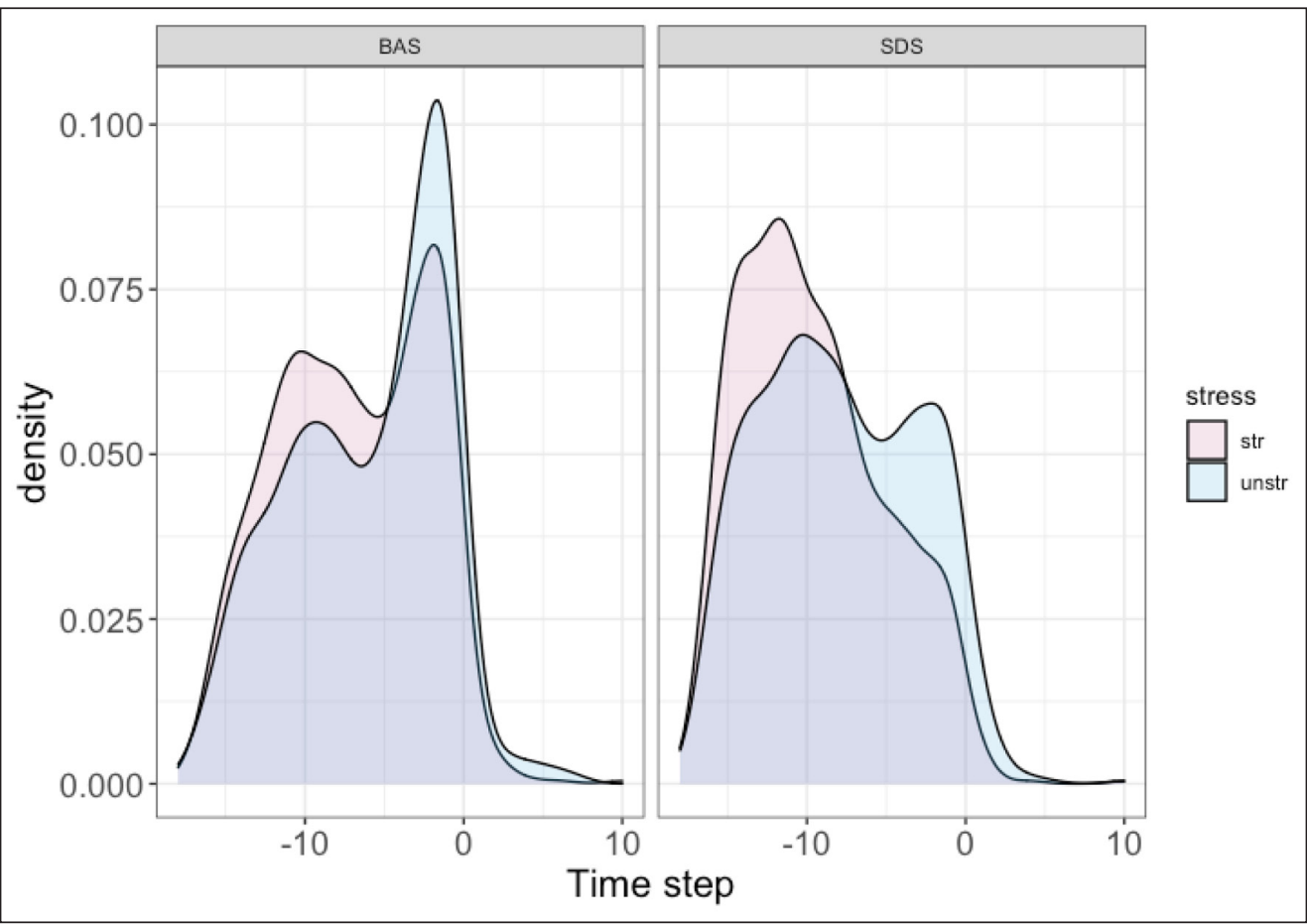

Figure 9: Onset of nasalization per stress condition and dialect group. The zero time-point corresponds with vowel-nasal boundary.

Because Bongiovanni (2021) had found an effect of stress, the data was also inspected for this linguistic variable. The left panel in Figure 9 shows overlapping distributions in Buenos Aires Spanish across stress conditions. For Santo Domingo Spanish (right panel), on the other hand, onset of nasalization takes place earlier in the stressed condition. This finding may indicate that for the Dominican data, nasality in the pre-nasal vowel is an intended property of the vowel that is amplified under stress, as was suggested in Bongiovanni (2021). Once again, the data show bimodal distributions.

To statistically test the patterns above, onset of nasalization was entered into a mixed effects linear regression model as dependent variable. Fixed effects were dialect group and pre-consonant environment, and there were by-speaker and by-word random intercepts. Additionally, the interaction terms of pre-consonant environment by dialect, stress by dialect, and pre-consonant environment and stress were included in the model (see Table 5). As with previous models, statistical significance was set at $\alpha=.05$. The intercept refers to Buenos Aires in pre-coronal environment.

All main effects were statistically significant, as were the interaction terms. Regarding the direction of effects, pre-dorsal environment and stressed syllables exhibit statistically significant earlier onset of nasalization, in agreement with the visual exploration of the data. The interaction 


\begin{tabular}{llllll} 
Fixed effects & Estimate & $\boldsymbol{S E}$ & df & $\boldsymbol{t}$-value & $\boldsymbol{p}$ \\
\hline (Intercept) & -5.28 & 0.47 & 76.64 & -11.26 & $<.001$ \\
Dialect Santo Domingo & -3.32 & 0.64 & 69.99 & -5.17 & $<0.001$ \\
Stress Unstressed & 0.88 & 0.30 & 1790.26 & 2.98 & $<0.01$ \\
Environment velar & -3.11 & 0.29 & 1790.09 & -10.52 & $<.001$ \\
Santo Domingo*velar & 2.16 & 0.34 & 1790.22 & 6.31 & $<.001$ \\
Santo Domingo * unstressed & 1.51 & 0.34 & 1790.26 & 4.45 & $<.001$ \\
Unstressed * Velar & -0.78 & 0.34 & 1790.28 & -2.28 & $<0.05$
\end{tabular}

Table 5: Mixed effects regression model for onset of velum lowering.

term of dialect by pre-consonantal environment, however, shows the trend in the opposite direction to what was expected. It remains unclear why the pre-dorsal environment for the [y]-dialect shows a trend of a later onset of nasalization.

In light of the finding of little to no weakening of the nasal consonant, Santo Domingo Spanish nonetheless exhibits an earlier onset of nasalization raises the possibility of a longer nasal gesture for this dialect group. To this end, the whole nasalization gesture (i.e., onset to completion) was examined. A maximum energy reading is assumed to index completion of velum lowering. Two scenarios are thus possible. Santo Domingo Spanish may exhibit a maximum reading earlier than Buenos Aires, which would indicate a similar sized gesture rendering the difference between dialects one of alignment of gestures. Or, Santo Domingo Spanish may show completion of velum lowering at the same time or later than Buenos Aires Spanish, indicating that Santo Domingo Spanish exhibits a longer gesture, and consequently, longer nasalization. For this purpose, an additional landmark was operationalized: completion of nasalization. To remind the reader, onset of nasalization was the first time point at $15 \%$ of the range between the minimum and the maximum nasal energy reading over the span of individual vowel-consonant sequences (that is, for each individual token). Completion of the gesture was defined as the time point at $80 \%$ of the range (cf. Delvaux et al., 2008; Honorof, 1999; Solé, 1992).

Figure 10 visualizes these data. On the left panel, we can see the dialectal differences in onset of nasalization. As previously presented, Santo Domingo (blue) exhibits earlier onset of nasalization. To the right of Figure 10, on the other hand, dialect groups show overlapping distributions, indicating that dialects achieved completion of the velum lowering gesture roughly at the same time. The time step difference at the offset of the gesture decreased by a decimal point (1.7 versus 1.6 and not a statistically significant difference, $t(1611.7)=0.65$, $p=.51$ ). All in all, these patterns suggest that the gesture is longer for Santo Domingo Spanish than for Buenos Aires Spanish. 


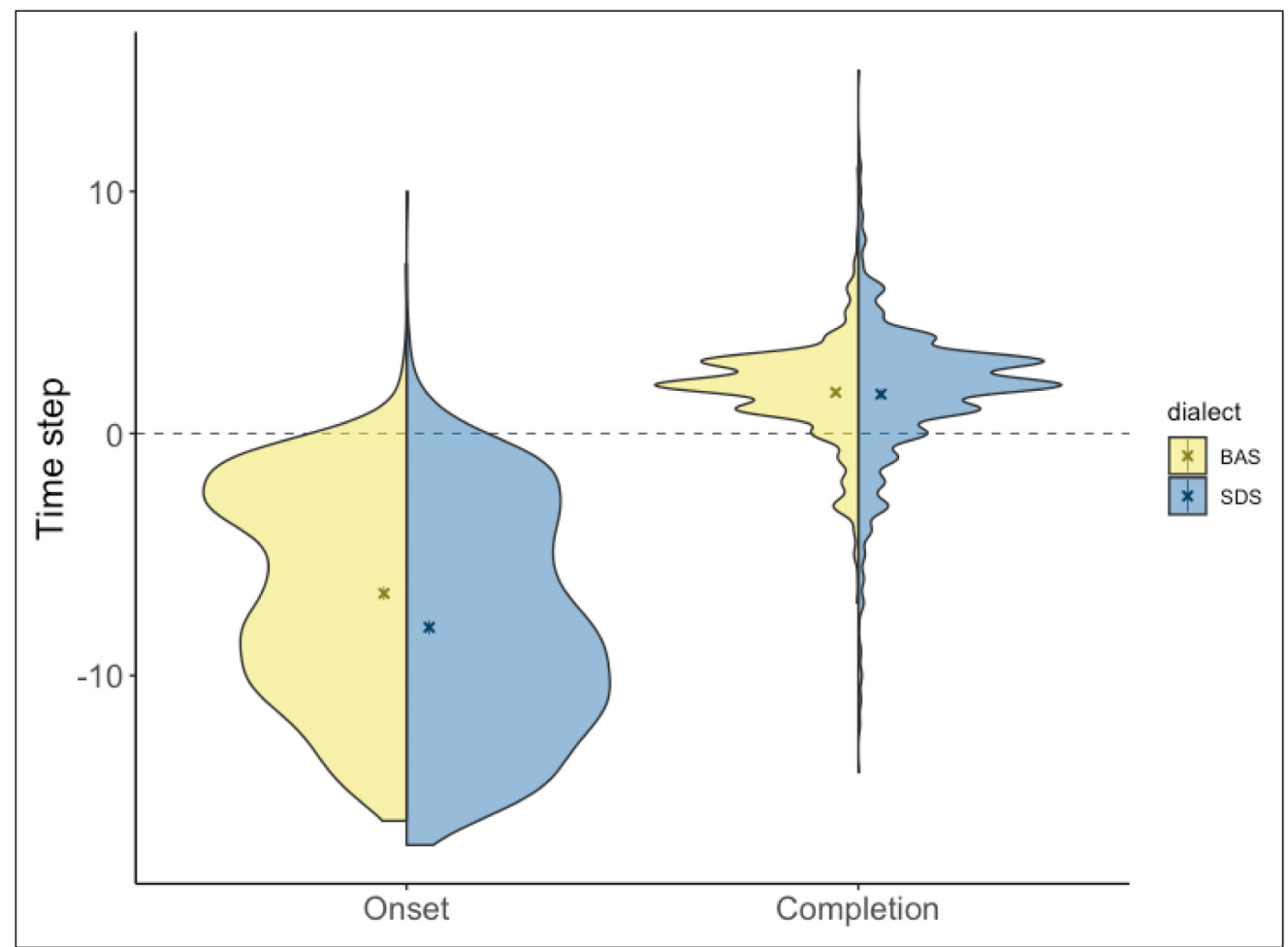

Figure 10: Onset (left), and completion (right) of nasalization. The zero time-point (dashed line) corresponds to the vowel-nasal boundary. Crosses represent the mean.

\section{Discussion}

This study examined covariation between weakening of the nasal consonant and anticipatory vowel nasalization in two dialects of Spanish, a velarizing and an alveolarizing dialect. Summarized briefly, the analysis of a corpus of nasometric data showed that when the nasal consonant weakened (i.e., becomes shorter or less constricted) onset of nasalization was elicited earlier, which was a trend in both dialects. Additionally, there was great acoustic overlap across groups in terms of nasal consonant weakening. With regard to the timecourse of nasalization, the trend of Santo Domingo exhibiting earlier onset of nasalization in Bongiovanni (2021) also obtained with these data, as well as when the pre-consonantal environments were examined.

The core issue this study sought to examine were dialectal differences in covariation between $/ \mathrm{n} /$ weakening and nasalization. The traditional view in Spanish phonology precludes [n]-dialects from undergoing the trading relationship. At the same time, phonetic findings in other languages (e.g., Beddor, 2009; Beddor, Coetzee, Styler, McGowan, \& Boland, 2018) predicted the same trend of covariation for the two dialects under study here. The alveolarizing dialect (Buenos Aires Spanish) was indeed susceptible of a trade-off relationship, even if backing of the nasal 
consonant is not part of the derivation. Though not necessarily the present case for Buenos Aires Spanish, or any other [n]-dialect, what these data suggest is that the path to nasalized vowels may or may not include a prior stage of velarization of the nasal consonant, and as such, potentially open to [n]-dialects (c.f. Hajek, 1997; Uber, 1984). This is not to say that the role of the velar variant should be discarded. The finding that the pre-dorsal environment also led to greater temporal reduction and greater nasalization-in both dialects-points in the direction of the velar variant facilitating the weakening process, also a finding in research on other languages (c.f. Asturian, Cadierno \& Prieto, 1991; Mandarin Chinese, Zhang, 2000). Thus, velarization was likely the gateway mechanism for greater nasalization, at least in the [n]-dialect under study, but the covariation relationship obtains independently from it.

Several other findings are also worth pointing out, such as the bimodal distributions in the time-course of nasalization. Starting with the Buenos Aires data, the patterns in Figure 7 may indicate that this [n]-dialect also exhibits instances of early onset of nasalization, and even speakers that are 'early onsetters.' This possibility would also explain the instances of early onset of nasalization in the pre-coronal environment and stress condition for this dialect group. Thus, there is a potential for more intra-dialect variation than anticipated, which augurs fruitful avenues for future research. Moving on to the Santo Domingo data, the acoustic overlap in preconsonantal environments suggests that speakers may not have variation between velar and coronal nasal consonants, at least not to the extent predicted in the previous literature. The fact remains that this study does not have independent verification of place of articulation of the nasal consonant, and thus, the nasal consonant could have been produced as coronal regardless of the articulatory details of the following consonant. This possibility raises the issue of whether or not the characterization of Santo Domingo as a velarizing dialect is accurate. However, Hispanic linguistics scholars coincide that Santo Domingo Spanish is a velarizing dialect (Alba, 2016; Haché de Yunén, personal communication; Willis, personal communication). In the absence of independent verification of place of articulation, these all remain conjectures. In future research, this issue will be addressed by including articulatory data.

An unexpected finding were the rather constricted word-final nasal consonants in the Santo Domingo data, when all previous research augured weakened—if not elided—nasal consonants. Nevertheless, as surprising as this result may be, it does not interfere with the interpretation of results. On the contrary, it underscores the finding that extent of nasalization in the Santo Domingo Spanish data cannot be attributed solely to nasal consonant weakening. A plausible explanation rests with the putative phonological differences in the interpretation of nasality across dialects, i.e., phonologized for Santo Domingo and coarticulatory for Buenos Aires (c.f. Lederer, 2000, cited in Lederer, 2003; Bongiovanni, 2021). These data suggest that for Santo Domingo, and potentially other [n]-dialects, anticipatory nasalization is not merely a marker of nasal consonant weakening. Another finding pointing in the direction of nasalization as a 
required configuration of the vowel (as opposed to being linked to the consonantal closure) is the finding of a longer gesture for Santo Domingo.

The contrast with previous literature regarding nasal consonant weakening remains an open question. Several facts may have contributed to this outcome. Firstly, the speech style and language attitudes may have conspired. Reports of pervasive nasal consonant weakening originate in casual speech. Laboratory techniques for data elicitation, such as the reading task employed in this study, lead to (more) careful speech, thus favoring more attention to speech, and consequently, less 'vernacular' speech patterns. Additionally, speaker attitudes arguably may have contributed to heightened attention to speech. Dominican speakers are well-known for their linguistic insecurity (Alba, 2004; Büdenbender, 2010; Bullock \& Toribio, 2014; Toribio, 2000). With Argentines, research has shown conflicting forces regarding their view of their own variety. While they often judge North-Central Peninsular Spanish as 'more correct' and even preferable, they also exhibit great linguistic pride (Bugel, 2012; Llull \& Pinardi, 2014). Also, Bugel (2012) shows that on implicit measurements Argentine listeners judge the Argentine guise more positively. In this study, crucially, the researcher-myself-was a member of the speech community in one dialectal area (i.e., Buenos Aires), but an outsider in the other. Taken together, these facts may have facilitated (more) careful speech, and consequently, less nasal consonant weakening than anticipated for the Santo Domingo group. Yet, the extent to which the previous literature may have over-reported nasal consonant weakening should not be discounted either. Considering the impressionist nature of data coding, velar nasals may have been misperceived as nasalized vowels (Ohala \& Ohala, 1993) and reported as such (see Goodin-Mayeda, 2016, for a similar observation). Additionally, while EPG can accurately depict place of articulation and degree of contact, its precision wavers when the constriction is located towards the posterior end of the vocal tract (c.f. Colantoni \& Kochetov, 2012, p. 21). The findings in this study are at odds with the frequency of weakening of word-final nasal consonant as reported in previous work, both impressionistic and instrumental, and highlight the need to diversify methodologies.

Beyond Spanish linguistics, there are two final points of discussion. First, the present findings speak to the well-documented intermediate stage of sound change in nasalization of an inverse relationship between consonant weakening and the temporal extent of nasalization (c.f. Beddor, 2009). The patterns of covariation certainly constitute a reflex of said stage. At the same time, the longer gesture for Santo Domingo Spanish, despite the lack of nasal consonant weakening, adds layers of nuance. It could be that once nasality in the vowel has conventionalized, it is no longer dependent on consonantal weakening. In this scenario, regardless of whether the nasal consonant is weakened or not, onset of nasalization would obtain earlier (as long as it has conventionalized). As such, this scenario suggests the possibility that the cross-linguistic differences (dialectal, in the present case) in the timing of nasalization 
are not exclusively the result of a variably aligned constant-sized nasal gesture. Were this to be the case, the intermediate stage could be argued to have two moments: one in which nasalization is purely 'coarticulatory' and a second one with a phonological rule in which the vowel becomes nasalized preceding a nasal consonant (yet, still an oral vowel phoneme, or [NAS]; see Hajek, 1997, for a similar proposal). Additional experiments are necessary to fully pursue this possibility.

On a methodological note, there are many advantages to the use of the nasometer. First, the nasometer allows conducting fine grained acoustic analysis with speech data from larger samples of participants than other techniques, such as airflow, nasography, or EPG. Compared to the latter methods, nasometry is relatively more affordable and portable, opening the possibility for research in a fieldwork setting. Of course, like any other method, the nasometer does present drawbacks. Recording spontaneous speech is difficult with the nasometer, since it would be uncomfortable for the participant to hold the equipment up for long periods of time. Additionally, the bulky presence of the equipment in front of subjects' faces makes it even more important to manage their attention to speech and their understanding of the research goals. Then again, as researchers we can only pursue a handful of research questions at a time, but bringing this awareness into the research design and scope, this equipment certainly promises new avenues of research for laboratory studies in general.

In closing, variation in the temporal extent of Spanish nasalization has been ascribed to multiple sources, with covariation with the articulatory source and cross-linguistic (and phonological) differences being the most widely cited. The findings in this study bridge the gap between these two sources of variation: The time-course of nasalization does not rely solely on system-wide nasal consonant weakening. Intra-dialect behavior revealed that early onset of nasalization can still obtain in the absence of nasal consonant weakening. These insights would not have been made possible if not for nasometry, which opened the door to the acoustic analysis of the coarticulatory source together with its target. In addition to the instrumental contribution, an asset of the present investigation is the focus on cross-dialectal differences as key to understanding phonetic and phonological patterns, as well as extending existing research to additional Spanish [n]-[y] dialect pairs. 


\section{Additional File}

The additional file for this article can be found as follows:

- Appendix. Reading materials and individual speakers. DOI: https://doi.org/10.16995/ labphon.6444.s1

\section{Acknowledgements}

I would like to thank Kenneth de Jong, Karthik Durvasula, Yen-Hwei Lin, and Erik Willis for feedback at different points of the research process. I am also indebted to the feedback of the Associate Editor, Dr. Lisa Davidson, and to two anonymous reviewers for their careful reading of the manuscript. All errors remain my own.

\section{Competing Interests}

The author has no competing interests to declare.

\section{References}

Alba, O. (2004). Cómo hablamos los dominicanos: Un enfoque sociolingüístico. Santo Domingo: Grupo León Jimenes.

Alba, O. (2016). Una mirada panorámica al español antillano. Santo Domingo: Editora Nacional.

Baković, E. (2001). Nasal place neutralization in Spanish. In M. Fox, A. Williams \& E. Kaisser (Eds.), Proceedings of the 24th annual Penn linguistics colloquium (Penn working papers in linguistics) (pp. 1-12).

Bates, D., Mächler, M., Bolker, B., \& Walker, S. (2015). Fitting linear mixed-effects models using lme4. Journal of Statistical Software, 67(1), 1-48. DOI: https://doi.org/10.18637/jss.v067.i01

Beddor, P. (2007). Nasals and nasalization: The relation between segmental and coarticulatory timing. In J. Trouvain \& W. J. Barry (Eds.), Proceedings of the 16th international congress of phonetic sciences (ICPhS 2007), Saarbrücken, 6-10 August, 2007 (pp. 249-254) Dudweiler: Pirrot.

Beddor, P. (2009). A coarticulatory path to sound change. Language, 85(4), 785-821. DOI: https://doi.org/10.1353/lan.0.0165

Beddor, P. (2012). Perception grammars and sound change. In M.-J. Solé \& D. Recasens (Eds.), The initiation of sound change: Perception, production, and social factors, 323, 37-55. John Benjamins Publishing. DOI: https://doi.org/10.1075/cilt.323.06bed

Beddor, P., Coetzee, A. W., Styler, W., McGowan, K. B., \& Boland, J. E. (2018). The time course of individuals' perception of coarticulatory information is linked to their production: Implications for sound change. Language, 94(4), 931-968. DOI: https://doi.org/10.1353/lan.2018.0051

Boersma, P., \& Weenink, D. (2016). Praat: Doing phonetics by computer (version 6.0.16). [Computer program]. (Retrieved 5 April 2016 from http://www.praat.org/). 
Bongiovanni, S. (2021). Acoustic investigation of anticipatory vowel nasalization in a Caribbean and a non-Caribbean dialect of Spanish. Linguistics Vanguard, 7(1). DOI: https://doi.org/10.1515/ lingvan-2020-0008

Büdenbender, E.-M. S. (2010). Comparing Dominican linguistic (in)security in the Dominican Republic and in the diaspora. In C. Borgonovo, M. E. nol Echevarría \& P. Prévost (Eds.), 12th Hispanic Linguistics Symposium (pp. 148-159). Somerville, MA: Cascadilla Proceedings Project.

Bugel, T. (2012). Buenas y no tan buenas variedades del español: Opiniones y actitudes en Montevideo y Buenos Aires. Revista Internacional de Lingüística Iberoamericana, 83-107.

Bullock, B. E., \& Toribio, A. J. (2014). Dominican Spanish. In M. Di Paolo \& A. K. Spears (Eds.), Languages and dialects in the US: Focus on diversity and linguistics (pp. 151-162). Routledge.

Busà, M. G. (2003). Vowel nasalization and nasal loss in Italian. In M.-J. Solé, D. Recasens \& J. Romero (Eds.), Proceedings of the 15th international congress of phonetic sciences (pp. 711-714). Barcelona: Causal Productions.

Cadierno, T., \& Prieto, P. (1991). Procesos de coarticulación en la asimilación de nasales en asturiano. Lletres asturianes: Boletín Oficial de l'Academia de la Llingua Asturiana, 39, 15-22.

Campos-Astorkiza, R. (2012). The phonemes of Spanish. In J. I. Hualde, A. Olarrea \& E. O’Rourke (Eds.), The handbook of Hispanic linguistics (p. 89-110). Chichester, West Sussex [England]: John Wiley \& Sons. DOI: https://doi.org/10.1002/9781118228098.ch5

Cedergren, H., \& Sankoff, D. (1975). Nasals: A sociolinguistic study of change in progress. In C. Ferguson, L. Hyman \& J. Ohala (Eds.), Papers from a symposium on nasals and nasalization (pp. 67-80). Stanford, CA: Stanford University.

Chen, M. (1973). Cross-dialectal comparison: A case study and some theoretical considerations. Journal of Chinese Linguistics, 38-63.

Clumeck, H. (1976). Patterns of soft palate movements in six languages. Journal of Phonetics, 4(4), 337-351. DOI: https://doi.org/10.1016/S0095-4470(19)31260-4

Cohn, A. C. (1993). Nasalisation in English: Phonology or phonetics. Phonology, 10(01), 43-81. DOI: https://doi.org/10.1017/S0952675700001731

Colantoni, L. (2011). Laboratory approaches to sound variation and change. In M. DíazCampos (Ed.), The handbook of Hispanic sociolinguistics. John Wiley \& Sons. DOI: https://doi. org/10.1002/9781444393446.ch1

Colantoni, L., \& Kochetov, A. (2012). Nasal variability and speech style: An EPG study of wordfinal nasals in two Spanish dialects. Italian Journal of Linguistics/Rivista di Linguistica, 24, 11-42.

Delvaux, V., Demolin, D., Harmegnies, B., \& Soquet, A. (2008). The aerodynamics of nasalization in French. Journal of Phonetics, 36(4), 578-606. DOI: https://doi.org/10.1016/j.wocn.2008.02.002

D'Introno, F., \& Sosa, J. M. (1988). Elisió de nasal o nasalizaciõ de vocal eN caraqueño. In R. Hammond \& M. Resnick (Eds.), Studies in Caribbean Spanish dialectology (pp. 24-34). Washington, DC [United States]: Georgetown University Press.

Foley, J. (1975). Nasalization as universal phonological process. In C. A. Ferguson, L. M. Hyman \& J. J. Ohala (Eds.), Násalfest: Papers from a symposium on nasals and nasalization (pp. 197-212). Language Universals Project, Stanford University. 
Goodin-Mayeda, C. E. (2016). Nasals and nasalization in Spanish and Portuguese: Perception, phonetics and phonology, 9. John Benjamins Publishing Company. DOI: https://doi.org/10.1075/ ihll.9

Haché de Yunén, A. (1981). La/n/ final de sílaba en el español de Santiago de los Caballeros. In O. Alba (Ed.), El español del Caribe (pp. 143-154). Santiago de los Caballeros: Universidad Católica Madre y Maestra.

Hajek, J. (1997). Universals of sound change in nasalization. Oxford [England]: Wiley.

Harris, J. W. (1984). Theories of phonological representation and nasal consonants in Spanish. In P. Baldi (Ed.), Papers from the XIIth Linguistic Symposium on Romance Languages (pp. 153-168). Amsterdam, Netherlands. DOI: https://doi.org/10.1075/cilt.26.13har

Hattori, S., Yamamoto, K., \& Fujimura, O. (1958). Nasalization of vowels in relation to nasals. The Journal of the Acoustical Society of America, 30(4), 267-274. DOI: https://doi. org/10.1121/1.1909563

Hernández, J. E. (2009). Measuring rates of word-final nasal velarization: The effect of dialect contact on in-group and out-group exchanges. Journal of Sociolinguistics, 13(5), 583-612. DOI: https://doi.org/10.1111/j.1467-9841.2009.00428.x

Honorof, D. N. (1999). Articulatory gestures and Spanish nasal assimilation (Unpublished doctoral dissertation). Yale University.

Hualde, J. I. (2014). Los sonidos del español. Cambridge [England]: Cambridge University Press. DOI: https://doi.org/10.1017/CBO9780511719943

Hualde, J. I., Simonet, M., \& Nadeu, M. (2011). Consonant lenition and phonological recategorization. Laboratory Phonology, 2(2), 301-329. DOI: https://doi.org/10.1515/labphon.2011.011

Hyman, R. L. (1956). [ $\eta]$ as an allophone denoting open juncture in several Spanish-American dialects. Hispania, 293-299. DOI: https://doi.org/10.2307/336007

Kochetov, A., \& Colantoni, L. (2011). Spanish nasal assimilation revisited: A cross-dialect electropalatographic study. Laboratory Phonology, 2(2), 487-523. DOI: https://doi.org/10.1515/ labphon.2011.018

Krakow, R. A. (1999). Physiological organization of syllables: A review. Journal of Phonetics, 27(1), 23-54. DOI: https://doi.org/10.1006/jpho.1999.0089

Lederer, J. S. (2003). The diachronic coronal-velar nasal relationship. In M.-J. Solé, D. Recasens \& J. Romero (Eds.), 15th international congress of phonetic sciences (p. 2801-2804). Universitat Autònoma de Barcelona.

Lipski, J. M. (2011). Socio-phonological variation in Latin American Spanish. In M. Díaz-Campos (Ed.), The handbook of Hispanic Sociolinguistics (pp. 72-97). John Wiley \& Sons. DOI: https://doi. org/10.1002/9781444393446.ch4

Llull, G., \& Pinardi, L. C. (2014). Actitudes lingüísticas en la Argentina. El español en Buenos Aires: Una aproximación a las representaciones de sus hablantes. Bergen Language and Linguistics Studies, 5. DOI: https://doi.org/10.15845/bells.v5i0.676

López Morales, H. (1980). Velarización de "n" en el español de Puerto Rico. LEA: Lingüística española actual, 2(2), 203-217. 
Muñiz-Cachón, C. (2002). Rasgos fónicos del español hablado en Asturias. Archivum: Revista de la Facultad de Filosofía y Letras, 52. 323-349.

Ohala, J. J., \& Ohala, M. (1993). The phonectics of nasal phonology: Theorems and data. In M. K. Huffman \& R. A. Krakow (Eds.), Nasals, nasalization, and the velum (pp. 225-249). Academic Press. DOI: https://doi.org/10.1016/B978-0-12-360380-7.50013-2

Onsuwan, C. (2005). Temporal relations between consonants and vowels in Thai syllables. University of Michigan.

Piñeros, C.-E. (2006). The phonology of nasal consonants in five Spanish dialects. In F. MartínezGil \& S. Colina (Eds.), Optimality-theoretic studies in Spanish phonology (pp. 146-171). DOI: https:// doi.org/10.1075/la.99.07pin

R Core Team. (2019). R: A language and environment for statistical computing. [Computer program]. Vienna, Austria.

Ramsammy, M. (2011). The realisation of coda nasals in Spanish (Unpublished doctoral dissertation). University of Manchester.

Ramsammy, M. (2013). Word-final nasal velarisation in Spanish. Journal of Linguistics, 49(1), 215-255. DOI: https://doi.org/10.1017/S0022226712000187

Rice, K. (1996). Default variability: The coronal-velar relationship. Natural Language \& Linguistic Theory, 14(3), 493-543. DOI: https://doi.org/10.1007/BF00133597

Ruhlen, M. (1973). Nasal vowels. Working Papers on Language Universals, 12, 1-36.

Salvador, G. (1987). Estudios dialectológicos. Madrid: Paraninfo.

Sampson, R. (1999). Nasal vowel evolution in Romance. Oxford [England]; New York [United States]: Oxford University Press.

Solé, M.-J. (1992). Phonetic and phonological processes: The case of nasalization. Language and Speech, 35(1-2), 29-43. DOI: https://doi.org/10.1177/002383099203500204

Solé, M.-J. (1995). Spatio-temporal patterns of velopharyngeal action in phonetic and phonological nasalization. Language and Speech, 38(1), 1-23. DOI: https://doi.org/10.1177/0023 83099503800101

Studebaker, G. A. (1985). A rationalized arcsine transform. Journal of Speech, Language, and Hearing Research, 28(3), 455-462. DOI: https://doi.org/10.1044/jshr.2803.455

Terrell, T. (1975). La nasal implosiva y final en el español de Cuba. Anuario de Letras, 13.

Toribio, A. J. (2000). Nosotros somos dominicanos: Language and self-definition among Dominicans. In A. Roca (Ed.), Research on Spanish in the United States: Linguistic issues and challenges (pp. 252-270). Somerville, MA: Cascadilla Press.

Trigo, R. L. (1988). The phonological derivation and behvior of nasal glides (Unpublished doctoral dissertation). Massachusetts Institute of Technology.

Uber, D. R. (1984). Phonological implications of the perception of -s and-n in Puerto Rican Spanish. In P. Baldi (Ed.), Papers from the xiith linguistic symposium on Romance languages, 26, 287. DOI: https://doi.org/10.1075/cilt.26.20rin 
Vaquero, M. (1996). Antillas. In M. Alvar (Ed.), Manual de dialectología hispanica: El español de América (pp. 51-67). Barcelona [Spain]: Ariel.

Wickham, H., Averick, M., Bryan, J., Chang, W., McGowan, L. D., François, R., ..., \& others. (2019). Welcome to the tidyverse. Journal of open source software, 4(43), 1686. DOI: https://doi. org/10.21105/joss.01686

Winter, B. (2019). Statistics for linguists: An introduction using $r$. Routledge. DOI: https://doi. org/10.4324/9781315165547

Zhang, J. (2000). Non-contrastive features and categorical patterning in Chinese diminutive suffixation: Max [f] or ident [f]? Phonology, 17(3), 427-478. DOI: https://doi.org/10.1017/ S0952675701003979 